\title{
Health Benefits of Exercise
}

\author{
Gregory N. Ruegsegger ${ }^{1}$ and Frank W. Booth ${ }^{1,2,3,4}$ \\ ${ }^{1}$ Department of Biomedical Sciences, University of Missouri, Columbia, Missouri 65211 \\ ${ }^{2}$ Department of Medical Pharmacology and Physiology, University of Missouri, Columbia, Missouri 65211 \\ ${ }^{3}$ Department of Nutrition and Exercise Physiology, University of Missouri, Columbia, Missouri 65211 \\ ${ }^{4}$ Dalton Cardiovascular Research Center, University of Missouri, Columbia, Missouri 65211 \\ Correspondence: boothf@missouri.edu
}

Overwhelming evidence exists that lifelong exercise is associated with a longer health span, delaying the onset of 40 chronic conditions/diseases. What is beginning to be learned is the molecular mechanisms by which exercise sustains and improves quality of life. The current review begins with two short considerations. The first short presentation concerns the effects of endurance exercise training on cardiovascular fitness, and how it relates to improved health outcomes. The second short section contemplates emerging molecular connections from endurance training to mental health. Finally, approximately half of the remaining review concentrates on the relationships between type 2 diabetes, mitochondria, and endurance training. It is now clear that physical training is complex biology, invoking polygenic interactions within cells, tissues/organs, systems, with remarkable cross talk occurring among the former list.

$T^{\text {he }}$ he aim of this introduction is briefly to document facts that health benefits of physical activity predate its readers. In the 5 th century BC, the ancient physician Hippocrates stated: "All parts of the body, if used in moderation and exercised in labors to which each is accustomed, become thereby healthy and well developed and age slowly; but if they are unused and left idle, they become liable to disease, defective in growth and age quickly." However, by the 21 st century, the belief in the value of exercise for health has faded so considerably, the lack of exercise now presents a major public health problem (Fig. 1) (Booth et al. 2012). Similarly, the lack of exercise was classified as an actual cause of chronic diseases and death (Mokdad et al. 2004).

Published in 1953, Jeremy N. Morris and colleagues conducted the first rigorous epidemiological study investigating physical activity and chronic disease risk, in which coronary heart disease (CHD) rates were increased in physically inactive bus drivers versus active conductors (Morris et al. 1953). Since this pioneering report, a plethora of evidence shows that physical inactivity is associated with the development of 40 chronic diseases (Table 1), including major noncommunicable diseases such as type 2 diabetes (T2D) and CHD, and as premature mortality (Booth et al. 2012).

Editors: Juleen R. Zierath, Michael J. Joyner, and John A. Hawley

Additional Perspectives on The Biology of Exercise available at www.perspectivesinmedicine.org

Copyright (C) 2018 Cold Spring Harbor Laboratory Press; all rights reserved; doi: 10.1101/cshperspect.a029694

Cite this article as Cold Spring Harb Perspect Med 2018;8:a029694 
G.N. Ruegsegger and F.W. Booth

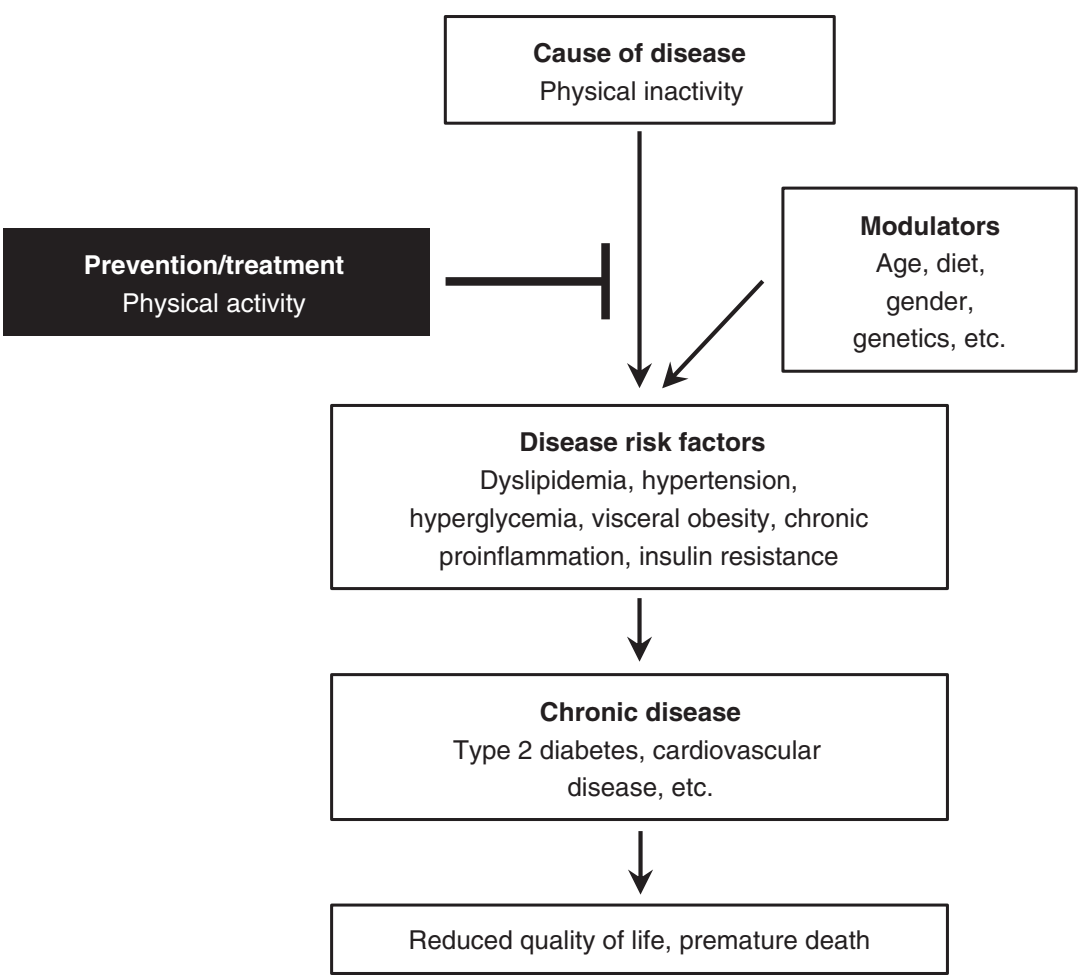

Figure 1. Simplistic overview of how physical activity can prevent the development of type 2 diabetes and one of its complications, cardiovascular disease. Physical inactivity is an actual cause of type 2 diabetes, cardiovascular disease, and tens of other chronic conditions (Table 1) via interaction with other factors (e.g., age, diet, gender, and genetics) to increase disease risk factors. This leads to chronic disease, reduced quality of life, and premature death. However, physical activity can prevent and, in some cases, treat disease progression associated with physical inactivity and other genetic and environmental factors.

In this review, we highlight the far-reaching health benefits of physical activity. However, note that the studies cited here represent only a fraction of the $>100,000$ studies showing positive associations between the terms "exercise" and "health." In addition, we discuss how exercise promotes complex integrative responses that lead to multisystem responses to exercise, an underappreciated area of medical research. Finally, we consider how strategies that "mimic" parts of exercise training compare with physical exercise for their potential to combat metabolic disease.

\section{EXERCISE IMPROVES CARDIORESPIRATORY FITNESS}

There is arguably no measure more important for health than cardiorespiratory fitness (CRF) (commonly measured by maximal oxygen uptake, $\mathrm{VO}_{2 \max }$ ) (Blair et al. 1989). For example, Myers et al. (2002) showed that each 1 metabolic equivalent (1 MET) increase in exercise-test performance conferred a $12 \%$ improvement in survival, stating that " $\mathrm{VO}_{2 \max }$ is a more powerful predictor of mortality among men than other established risk factors for cardiovascular disease (CVD)." Low CRF is also well established as an independent risk factor of T2D (Booth et al. 2002) and CVD morbidity and mortality (Kodama et al. 2009; Gupta et al. 2011). Similarly, Kokkinos et al. (2010) reported that men who transitioned from having low to high CRF decreased their mortality risk by $\sim 50 \%$ over an 8 yr period, whereas men who transitioned from having high to low CRF increased their mortality risk by $\sim 50 \%$. 
Table 1. Worsening of 40 conditions caused by the lack of physical activity with growth, maturation, and aging throughout life span

1. Accelerated biological aging/premature death

2. Aerobic (cardiorespiratory) fitness $\left(\mathrm{VO}_{2 \max }\right)$

3. Arterial dyslipidemia

4. Balance

5. Bone fracture/falls

6. Breast cancer

7. Cognitive dysfunction

8. Colon cancer

9. Congestive heart failure

10. Constipation

11. Coronary (ischemic) heart disease

12. Deep vein thrombosis

13. Depression and anxiety

14. Diverticulitis

15. Endometrial cancer

16. Endothelial dysfunction

17. Erectile dysfunction

18. Gallbladder diseases

19. Gestational diabetes

20. Hemostasis

21. Hypertension

22. Immunity

23. Insulin resistance

24. Large arteries lose more compliance with aging

25. Metabolic syndrome

26. Nonalcoholic fatty liver disease

27. Obesity

28. Osteoarthritis

29. Osteoporosis

30. Ovarian cancer

31. Pain

32. Peripheral artery disease

33. Preeclampsia

34. Polycystic ovary syndrome

35. Prediabetes

36. Rheumatoid arthritis

37. Sarcopenia

38. Stroke

39. Tendons being less stiff

40. Type 2 diabetes

The breadth of the list implies that a single molecular target will not substitute for appropriate daily physical activity to prevent the loss of all listed items.

Importantly then, from the above paragraph, physical activity and inactivity are major environmental modulators of CRF, increasing and decreasing it, respectively, often through independent pathways. Findings from rats se- lectively bred for high or low intrinsic aerobic capacity show that rats bred for high capacity, which are also more physically active, have $28 \%-42 \%$ increases in life span compared to low-capacity rats (Koch et al. 2011). Endurance exercise is well recognized to improve CRF and cardiometabolic risk factors. Exercise improves numerous factors speculated to limit $\mathrm{VO}_{2 \max }$ including, but not restricted to, the capacity to transport oxygen (e.g., cardiac output), oxygen diffusion to working muscles (e.g., capillary density, membrane permeability, muscle myoglobin content), and adenosine triphosphate (ATP) generation (e.g., mitochondrial density, protein concentrations).

Data from the HERITAGE Family Study has provided some of the first knowledge of genes associated with $\mathrm{VO}_{2 \max }$ plasticity because of endurance-exercise training. Following 6 wk of cycling training at $70 \%$ of pretraining $\mathrm{VO}_{2 \max }$, Timmons et al. (2010) performed messenger RNA (mRNA) expression microarray profiling to identify molecules potentially predicting $\mathrm{VO}_{2 \max }$ training responses, and then assessed these molecular predictors to determine whether DNA variants in these genes correlated with $\mathrm{VO}_{2 \max }$ training responses. This approach identified 29 mRNAs in skeletal muscle and 11 single-nucleotide polymorphisms (SNPs) that predicted $\sim 50 \%$ and $\sim 23 \%$, respectively, of the variability in $\mathrm{VO}_{2 \max }$ plasticity following aerobic training (Timmons et al. 2010). Intriguingly, pretraining levels of these mRNAs were greater in subjects that achieved greater increases in $\mathrm{VO}_{2 \max }$ following aerobic training, and of the 29 mRNAs, $>90 \%$ were unchanged with aerobic training, suggesting that alternative exercise intervention paradigms or pharmacological strategies may be needed to improve $\mathrm{VO}_{2 \max }$ in individuals with a low responder profile for the identified predictor genes (Timmons et al. 2010). Keller et al. (2011) found that, in response to endurance training, improvements in $\mathrm{VO}_{2 \max }$ were associated with effectively upregulating proangiogenic gene networks and miRNAs influencing the transcription factordirected networks for runt-related transcription factor 1 (RUNX1), paired box gene 3 (PAC3), and sex-determining region $\mathrm{Y}$ box 9 (SOX9). 
Collectively, these results led the investigators to speculate that improvements in skeletal muscle oxygen sensing and angiogenesis are primary determinates in training responses in $\mathrm{VO}_{2 \max }$ (Keller et al. 2011).

Clinically important concepts have emerged from the pioneering HERITAGE Family Study. One new clinical concept is that a threshold dose-response relationship influences the percentage of subjects responding with an increase in $\mathrm{VO}_{2 \max }$ to endurance training volumes (with volume being defined here as the product of intensity $\times$ duration), as previously published (Slentz et al. 2005, 2007). Ross et al. (2015) later extended the aforementioned Slentz et al. studies. After a 24-wk-long endurance training study (Ross et al. 2015), percentages of women and men identified as nonresponders to the training (i.e., defined as not increasing their $\mathrm{VO}_{2 \text { peak }}$ ) progressively fell inversely to a two stepwise progressive increase in endurance-exercise training volume, as described next. Thirty-nine percent (15 of 39) of training subjects did not increase their $\mathrm{VO}_{2 \text { peak }}$ in response to the low-amount, low-intensity training; $18 \%$ (9 of 51) had no increase in $\mathrm{VO}_{2 \text { peak }}$ in the group having highamount, low-intensity training; and 0\% (0 of 31) who underwent high-amount, high-intensity training did not increase their $\mathrm{VO}_{2 \text { peak. }} \mathrm{A}$ biological basis for the dose-response relationship in the previous sentence could be made from an analysis of interval training (IT) and IT/continuous-training studies published from 1965 to 2012 (Bacon et al. 2013). A second older concept is being reinvigorated; Bacon et al. (2013) indicate that different endurance-exercise intensities and durations are needed for different systems in the body. They suggest that very short periods of high-intensity endurance-type exercise may be needed to reach a threshold for peripheral metabolic adaptations, but that longer training durations at lower intensities are required to see large changes in maximal cardiac output and $\mathrm{VO}_{2 \max }$.

A comparable example exists for resistance training. Maximal resistance loads require a minimum of $2 \mathrm{~min} /$ per wk for each muscle group recruited by a specific maneuver to obtain a strength training adaptation [ 8 contrac- tions/set $\times 2 \mathrm{sec} /$ contraction $\times 3$ sets/day) $\times 2$ days $/$ wk $)=96 \mathrm{sec}]$. As of 2016, one opinion from Sarzynski et al. (2016) for the molecular mechanisms by which endurance exercise drives $\mathrm{VO}_{2 \max }$ include, but are not limited to, calcium signaling, energy sensing and partitioning, mitochondrial biogenesis, angiogenesis, immune functions, and regulation of autophagy and apoptosis.

Perhaps more importantly, lifelong aerobic exercise training preserves $\mathrm{VO}_{2 \max }$ into old age. CRF generally increases until early adulthood, then declines the remainder of life in sedentary humans (Astrand 1956). The age-related decline in $\mathrm{VO}_{2 \max }$ is not trivial, as Schneider (2013) reported a $\sim 40 \%$ decline in healthy males and females spanning from 20 to $70 \mathrm{yr}$ of age. However, cross-sectional data show that with lifelong aerobic exercise training, trained individuals often have the same $\mathrm{VO}_{2 \max }$ as a sedentary individual four decades younger (Booth et al. 2012). Myers et al. (2002) found that low estimated $\mathrm{VO}_{2 \max }$ increases mortality 4.5-fold compared to high estimated $\mathrm{VO}_{2 \max }$. They concluded, "Exercise capacity is a more powerful predictor of mortality among men than other established risk factors for cardiovascular disease." Given the strong association between CRF, chronic disease, and mortality, we feel identifying the molecular transducers that cause age-related reductions in CRF may have profound implications for improving health span and delaying the onset of chronic disease. In two of our recent papers, transcriptomics was performed on the triceps muscle (Toedebusch et al. 2016) and on the cardiac left ventricle (Ruegsegger et al. 2017). We were addressing the question of what molecule initiates the beginning of the lifelong decline in aerobic capacity with aging. Aerobic capacity $\left(\mathrm{VO}_{2 \max }\right)$ involves, at a minimum, the next systems/ tissues, as oxygen travels through the mouth, airways, pulmonary membrane, pulmonary circulation, left heart, aorta/arteries/capillaries, and sarcoplasm/myoglobin to mitochondria. We allowed female rats access, or no access, to running wheels from 5 to 27 wk of age. Surprisingly, voluntary running had no effect on the delay in the beginning of the lifetime decrease in 
$\mathrm{VO}_{2 \max }$. Our skeletal muscle transcriptomics elicited no molecular targets, whereas gene networks suggestive of influencing maximal stroke volume were identified in the left ventricle transcriptomics (Ruegsegger et al. 2017).

Publications concerning the effects of exercise on the brain (from 54 to 216 papers listed on PubMed from 2007 to 2016) have increased $400 \%$. In addition, a 2016 study (Schuch et al. 2016) of three previous papers reported that humans with low- and moderate-CRF had $76 \%$ and $23 \%$, respectively, increased risk of developing depression compared to high CRF in three publications. With this forming trend, the next section will consider exercise and brain health.

\section{EXERCISE IMPROVES MENTAL HEALTH}

Many studies support physical activity as a noninvasive therapy for mental health improvements in cognition (Beier et al. 2014; Bielak et al. 2014; Tian et al. 2014), depression (Kratz et al. 2014; McKercher et al. 2014; Mura et al. 2014), anxiety (Greenwood et al. 2012; Nishijima et al. 2013; Schoenfeld et al. 2013), neurodegenerative diseases (i.e., Alzheimer's and Parkinson's disease) (Bjerring and Arendt-Nielsen 1990; Mattson 2014), and drug addiction (Zlebnik et al. 2012; Lynch et al. 2013; Peterson et al. 2014). In 1999, van Praag et al. (1999) showed the survival of newborn cells in the adult mouse dentate gyrus, a hippocampal region important for spatial recognition, is enhanced by voluntary wheel running. Similarly, spatial pattern separation and neurogenesis in the dentate gyrus are strongly correlated in 3-mo-old mice following $10 \mathrm{wk}$ of voluntary wheel running (Creer et al. 2010), and the development of new neurons in the dentate gyrus is coupled with the formation of new blood vessels (Pereira et al. 2007). Many exercise-related improvements in cognitive function have been associated with local and systemic expression of growth factors in the hippocampus, notably, brain-derived neurotrophic factor (BDNF) (Neeper et al. 1995; Cotman and Berchtold 2002). BDNF promotes many developmental functions in the brain, including neuronal cell survival, differen- tiation, migration, dendritic arborization, and synaptic plasticity (Park and Poo 2013). In rat hippocampus, regular exercise promotes a progressive increase in BDNF protein for up to at least 3 mo (Berchtold et al. 2005). In an opposite manner, BDNF mRNA in the hippocampus is rapidly decreased by the cessation of wheel running, suggesting BDNF expression is tightly related to exercise volume (Widenfalk et al. 1999).

Findings by Wrann et al. (2013) highlight one mechanism by which endurance exercise may up-regulate BDNF expression. To summarize, Wrann et al. (2013) noted that exercise increases the activity of the estrogen-related receptor $\alpha(E R R \alpha) /$ peroxisome proliferatoractivated receptor $\gamma$ coactivator $1 \alpha$ (PGC- $1 \alpha)$ complex, in turn increasing levels of the exercise-secreted factor FNDC5 in skeletal muscle and the hippocampus, whose cleavage products provide beneficial effects in the hippocampus by increasing BDNF gene expression. While future research should determine whether the FNDC5 cleavage-product was produced locally in hippocampal neurons or was secreted into the circulation, this finding eloquently displays one mechanism responsible for brain health benefits following exercise. Similarly, work by van Praag and colleagues suggests that exercise or pharmacological activation of AMP-activated protein kinase (AMPK) in skeletal muscle enhances indices of learning and memory, neurogenesis, and gene expression related to mitochondrial function in the hippocampus (Kobilo et al. 2011, 2014; Guerrieri and van Praag 2015).

Insulin-like growth factor 1 (IGF-1), is central to many exercise-induced adaptations in the brain. Like BDNF, physical activity increases circulatory IGF-1 levels and both exercise and infusion of IGF-1 increase $\mathrm{BrdU}^{+}$cell number and survivability in the hippocampus (Trejo et al. 2001). Similarly, the protective effects of exercise on various brain lesions are nullified by anti-IGF-1 antibody (Carro et al. 2001).

In 1979, Greist et al. (1979) provided evidence that running reduced depression symptoms similarly to psychotherapy. However, the precise mechanisms by which exercise prevents and/or treats depression remain largely unknown. Of the proposed mechanisms, increases 
G.N. Ruegsegger and F.W. Booth

in the availability of brain neurotransmitters and neurotrophic factors (e.g., BDNF, dopamine, glutamate, norepinephrine, serotonin) are perhaps the best studied. For example, tyrosine hydroxylase ( $\mathrm{TH})$ activity, the rate-limiting enzyme in dopamine formation, in the striatum, an area of the brain's reward system, is increased following 7 days of treadmill running in an intensity-dependent manner (Hattori et al. 1994). Voluntary wheel running is also highly rewarding in rats, and voluntary wheel running in rats lowers the motivation to selfadminister cocaine, suggesting exercise may be a viable strategy in the fight against drug addiction (Larson and Carroll 2005).

Similar to the above examples, secreted factors from skeletal muscle have been linked to the regulation of depression. Agudelo et al. (2014) showed that exercise training in mice and humans, and overexpression of skeletal muscle PGC- $1 \alpha 1$, leads to robust increases in kynurenine amino transferase (KAT) expression in skeletal muscle, an enzyme whose activity protects from stress-induced increases in depression in the brain by converting kynurenine into kynurenic acid. Additionally, overexpression of PGC- $1 \alpha 1$ in skeletal muscle left mice resistant to stress, as evaluated by various behavioral assays indicative of depression (Agudelo et al. 2014). Simultaneously, they report gene expression related to synaptic plasticity in the hippocampus, such as BDNF and CamkII, were unaffected by chronic mild stress compared to wild-type mice. Collectively, these findings suggest exercise-induced increases in skeletal muscle PGC-1 $\alpha 1$ may be an important regulator of KAT expression in skeletal muscle, which, via modulation in plasma kynurenine levels, may alleviate stress-induced depression and promote hippocampal neuronal plasticity.

\section{TYPE 2 DIABETES, MITOCHONDRIA, AND EXERCISE}

\section{T2D Predictions Show a Pandemic}

In a 2001 Diabetes Care article (Boyle et al. 2001), investigators at the U.S. Centers for Disease Control (CDC) predicted 29 million U.S. cases of T2D would be present in 2050. Unfortunately, the 2001 prediction of 29 million was reached in 2012! For 2012, the American Diabetes Association reported that 29 million Americans had diagnosed and undiagnosed T2D, which was $9 \%$ of the American population (Dwyer-Lindgren et al. 2016). More rapid increases in $\mathrm{T} 2 \mathrm{D}$ are now predicted by the CDC than in the previous estimate. The CDC now predicts a doubling or tripling in T2D in 2050. The tripling would mean that one out of three U.S. adults would have T2D in their lifetime by 2050 (Boyle et al. 2010), which would be $>100$ million U.S. cases. The International Diabetes Federation (IDF) reports T2D cases worldwide. In 2015, the IDF reported that 344 and 416 million North American (including Caribbean) and worldwide adults, respectively, had T2D. Furthermore, the IDF predicts for 2040 that 413 and 642 million, respectively, will have T2D. In sum, T2D is now pandemic, and the pandemic will increase in numbers without current apparent action within the general public.

\section{Type 2 Diabetes Prevalence Is Based on a Strong Genetic Predisposition}

The Framingham study found that T2D risk in offspring was 3.5-fold and sixfold higher for a single and two diabetic parent(s), respectively, as compared to nondiabetic offspring (Meigs et al. 2000). Thus, T2D is gene-based.

Noncoding regions of the human genome contain $>90 \%$ of the $>100$ variants associated with both T2D and related traits that were observed in genome-wide association studies (Scott et al. 2016). Another 2016 paper (Kwak and Park 2016) lists at least 75 independent genetic loci that are associated with T2D. Taken together, T2D is a complex genetic disease ( $\mathrm{Scott}$ et al. 2016).

Type 2 Diabetes Is Modulated by Lifestyle, with Exercise as the More Powerful Lifestyle Factor

Three large-scale epidemiological studies have been performed on prediabetics, each in a different geographical location. The first study, 
and only study to have separate study arms for diet and exercise, was in China. The pure exercise intervention group had a $46 \%$ reduction in the onset of $\mathrm{T} 2 \mathrm{D}$, relative to the nontreated group, after 6 yr of the study (Pan et al. 1997). Diet alone reduced T2D by $31 \%$ in the Chinese study. The second study on T2D was the Finnish Diabetes Prevention Study. It found a 58\% reduction in T2D in the lifestyle intervention (combined diet and exercise) in its 522 prediabetic subjects after a mean study duration of $3.2 \mathrm{yr}$ (Tuomilehto et al. 2001). The latest of the three studies was in the U.S. Diabetes Prevention Program. The large randomized trial ( $n$ $=3150$ prediabetics) was stopped after $2.8 \mathrm{yr}$, because of harm to the control group. T2D prevalence in the high-risk adults was reduced by $58 \%$ with intensive lifestyle (diet and exercise) intervention, whereas the drug arm (metformin) of the study only reduced T2D by $31 \%$, both compared to the noninnervation group (Knowler et al. 2002). Thus, if differences in genetics in the above three differing ethnicities are not a factor, combined exercise and diet remain more effective in $\mathrm{T} 2 \mathrm{D}$ prevention than the drug metformin two decades ago.

\section{Exercise Increases Glucose by Signaling Independent of the Insulin Receptor}

A single exercise bout increases glucose uptake by skeletal muscle, sidestepping the insulin receptor and thus insulin resistance in T2D patients (Holloszy and Narahara 1965; Goodyear and Kahn 1998; Holloszy 2005). After insulin binding to its receptor, insulin initiates a downstream signaling cascade of tyrosine autophosphorylation of insulin receptor, insulin receptor substrate 1 (IRS-1) binding and phosphorylation, activation of a PI3K-dependent pathway, including key downstream regulators protein kinase B (Akt) and the Akt substrate of $160 \mathrm{kDa}$ (AS160), ultimately promoting glucose transporter 4 (GLUT4) translocation to the plasma membrane (Rockl et al. 2008; Stanford and Goodyear 2014). Despite normal GLUT4 levels, insulin fails to induce GLUT4 translocation in T2D (Zierath et al. 2000). However, exercise activates a downstream insulin- signaling pathway at AS160 and TBC1 domain family member 1 (TBC1D1) (Deshmukh et al. 2006; Maarbjerg et al. 2011), facilitating GLUT4 expression translocation to the plasma membrane independent of the insulin receptor. We contend that exercise could be considered as a very powerful tool to primarily attenuate the T2D pandemic.

\section{Complex Biology of T2D Interactions with the Complex Biology of Exercise}

An important consideration from the above is that T2D is such a genetically complex disease that a single gene has not been proven to be sufficiently causal to be effective, at this stage in time, to be a successful target for pharmacological treatment. The expectation for a single molecule target has been met for infectious diseases, which are often monogenic diseases. For example, a vaccine against smallpox was highly successful. Edward Jenner in 1796 produced the first successful vaccine. An important fact is that exercise is genetically complex. The literature allows us to speculate that exercise is at least as genetically complex as the approximately 75 genes associated with T2D (Kwak and Park 2016). An example indicating that exercise is complex biology follows. RNA sequencing analysis of all 119 vastus lateralis muscle biopsies found that endurance training for 4 days/wk for $12 \mathrm{wk}$ produced the differential expression of 3404 putative isoforms, belonging to 2624 different genes, many associated with oxidative ATP production in 23 women and men aged 29 yr old (Lindholm et al. 2016). Our notion is that over 2600 genes suggests complex biology.

\section{A "Case-Type" Study of the Molecular Underpinnings of Exercise, Mitochondria, and T2D Interactions}

A PubMed search for the terms "diabetes mitochondria exercise molecular" elicited 74 papers. We arbitrarily selected some of the most recent 50 (spanning from mid-2014 into January 2017), with the assumption they would be representative of any other papers that we did not 
find in our search. Papers fell into our two arbitrary categories of single gene studies versus "omic"-type studies. First, subcategories of studies that develop themes will be arbitrarily presented.

\section{Recent Studies Show Single Gene Manipulation Alters Mitochondrial Level and Running Performance}

Numerous reports in the past couple of years observed that single gene manipulations increase mitochondrial gene expression and activity, which was also associated with increased exercise performance/capacity. A few of these are presented below:

1. Irisin was shown to increase oxidative metabolism in myocytes and increase PGC- $1 \alpha$ mRNA and protein (Vaughan et al. 2014), which extends the first observation made earlier in adipose tissue by Spiegelman (Bostrom et al. 2012)

2. Patients with impaired glucose tolerance underwent low-intensity exercise training. Patients whose mitochondrial markers increased to levels that were measured in a separate cohort of nonexercised healthy individuals recovered normal glucose tolerance (Osler et al. 2015). In opposition, those patients whose mitochondria markers did not improve, remained with impaired glucose tolerance.

3. In 2003, muscle PGC- $1 \alpha$ mRNA was shown to be induced by endurance-exercise training in human skeletal muscle (Short et al. 2003). PGC- $1 \alpha$ was shown to have multiple isoforms (Lin et al. 2002). After a 60-min cycling bout, human vastus lateralis biopsies were taken from both sexes in their mid20s. Additional biopsies were taken $30 \mathrm{~min}$, and at 2, 6, and $24 \mathrm{hr}$ postexercise. At $30 \mathrm{~min}$ postexercise, PGC- $1 \alpha$-ex1b mRNA and PGC- $1 \alpha$ mRNA increased 468- and 2.4fold, respectively, whereas PGC- $1 \alpha$-ex $1 b$ protein and PGC-1 $\alpha$ protein increased 3.1fold and no change, respectively. Gidlund et al. (2015) interprets the above data as implying PGC-1 $\alpha$-ex1b could be responsible for other changes that have previously been recorded before the increase in total PGC- $1 \alpha$ postexercise.

4. Mice with knockout of the kinin B1 receptor gene had higher mitochondrial DNA quantification and of mRNA levels of genes related to mitochondrial biogenesis in soleus and gastrocnemius muscles and had higher exercise times to exhaustion, but did not have higher $\mathrm{VO}_{2 \max }$ (Reis et al. 2015).

5. Mice do not normally express cholesteryl ester transfer protein (CETP), which is a lipid transfer protein that shuttles lipids between serum lipoproteins and tissues. Overexpression of CETP in mice after $6 \mathrm{wk}$ on a high-fat diet increased treadmill running duration and distance, mitochondrial oxidation of glutamate/malate, but not palmitoylcarnitine oxidation, and doubled PGC- $1 \alpha$ mRNA concentration (Cappel et al. 2015).

6. The myokine musclin is a peptide secreted from exercising muscle during treadmill running. Removal of musclin release during running results in lowered $\mathrm{VO}_{2 \max }$, lower skeletal muscle mitochondrial content and respiratory complex protein expression, and reduced exercise tolerance (Subbotina et al. 2015).

7. Lactate dehydrogenase B (LDHB), which produces pyruvate from lactate, was overexpressed in mouse skeletal muscle. Increases in markers of skeletal muscle mitochondria were associated with increased running distance in a progressive speed test, and increased peak $\mathrm{VO}_{2}$ (Liang et al. 2016).

8. Another example of endurance-type exercise adaptations is the 2016 paper that transcription factor EB (TFEB) regulates metabolic flexibility in skeletal muscle independent of PGC-1 $\alpha$ during endurance-type exercise (Mansueto et al. 2017). Lack of metabolic flexibility, termed "metabolic inflexibility," is important because it is common in T2D. One definition of metabolic inflexibility is its inability to rapidly switch between glucose and fatty acid substrates for ATP production 
when nutrient availability changes from high blood glucose levels immediately after a meal to decreasing below $100 \mathrm{mg} / \mathrm{dl}$ when not eating for hours after a meal. A clinical consequence of T2D-induced metabolic inflexibility is prolonged periods of hyperglycemia, because skeletal muscle is more insulin insensitive in T2D. In contrast, after sufficient endurance exercise, skeletal muscle increases its insulin sensitivity by a second pathway that is independent of proximal postreceptor insulin signaling (see Stephenson et al. 2014 for further discussion).

Studies Showing that Manipulation of One Signaling Molecule Does Not Alter Expression of All Genes with Mitochondrial Functions Found in Skeletal Muscles of Wild-Type Animals to Exercise Training

A 2010 review article (Lira et al. 2010) concludes from gene-deletion studies that $\mathrm{p} 38 \gamma \mathrm{MAPK} /$ PGC- $1 \alpha$ signaling controls mitochondrial biogenesis' adaptation to endurance exercise in skeletal muscle. Two studies do not completely agree with the conclusion in the review article. The Pilegaard laboratory published a 2008 study (Leick et al. 2008) that did not confirm their hypothesis that PGC- $1 \alpha$ was required for every metabolic protein adaptive increase after endurance-exercise training by skeletal muscle. They reported that PGC- $1 \alpha$ was not required for endurance-training-induced increases in ALAS1, COXI, and cytochrome $c$ expression (Leick et al. 2008). Their interpretation, at that time, was that molecules other than PGC- $1 \alpha$ can exert exercise-induced mitochondrial adaptations. A second study published in 2012 rendered a similar verdict. A 12-day program of endurance training led to the middle portion of the gastrocnemius muscle demonstrating a similar $60 \%$ increase in mitochondrial density in both wild-type and PGC- $1 \alpha$ muscle-specific knockout mice (Myo-PGC-1 $\alpha \mathrm{KO}$ ) (Rowe et al. 2012). The paper concludes that PGC- $1 \alpha$ is dispensable for endurance-exercise's induction of skeletal muscle mitochondrial adaptations.

Exercise signaling targets have actions that are independent of PGC-1 $\alpha$, which is specific to endurance exercise. In 2002, two groups identified PGC-1 $\beta$, a transcriptional coactivator closely related to PGC-1 $\alpha$ (Kressler et al. 2002; Lin et al. 2002). Later in 2012, the PGC- $1 \alpha 4$ variant of PGC- $1 \alpha$ was found to induce skeletal muscle hypertrophy and strength (Ruas et al. 2012). The importance of the finding of a PGC- $1 \alpha$ variant is that it partially explains the phenotypic variation for differing types of exercise. Since the 1970s (Holloszy and Booth 1976), it has been appreciated that the biochemical and anatomical observations between endurance and resistance differed. For example, Holloszy and Booth (1976) noted in 1976 that, whereas endurance-type exercise markedly increased skeletal muscle mitochondrial density with very minor increases in muscle fiber diameter, strength-type exercise, in contrast, increased muscle fiber diameter without increases in skeletal muscle mitochondrial density. Taken together, a drug specific for PGC- $1 \alpha$ will not likely mimic separate physical training for endurance, strength/resistance, and coordination types of exercise in the same subject. Thus, the common usage of the term exercise capacity is a misnomer because endurance training and resistance training were shown to have different exercise capacity phenotypes very long ago.

In a 2015 Diabetes paper (Wong et al. 2015), Muoio's laboratory concluded that changes in glucose tolerance and total body fat depended upon how much energy is expended in contracting muscle rather than muscle mitochondrial content or substrate selection. A finding to support the previous sentence was the glucose tolerance tests (GTTs). MCK-PGC- $1 \alpha$ mice and their nontransgenic (NT) littermates were not different in GTT, with both being the most glucose intolerant after 10 wk of high-fat feeding. Adding $10 \mathrm{wk}$ of voluntary wheel running to the two high-fat-feed groups during the next 10 -wk period (weeks $11-20$ of the experiment) lowered the glucose intolerance, and then during weeks 21-30 of the experiment, glucose intolerance was further lowered by adding 25\% caloric restriction with the high-fat food and running during the final $10 \mathrm{wk}$. The percentage weight lost after $30 \mathrm{wk}$ of high-fat feeding was positively related to greater running distances. 
No single front-runner gene candidate could be identified by principle component analysis. Taken together, the paper suggests "doubts" that pharmacological exercise mimetics that increase muscle oxidative capacity will be effective antiobesity and/or antidiabetic agents. Rather, Muoio and investigators suggest energy expenditure by muscle contraction induces localized shifts in energy balance inside the muscle fiber, which then initiates a broad network of metabolic intermediates regulating nutrient sensing and insulin action. A further discussion of complex biology produced by polygenicity continues next.

\section{POLYGENICITY OF EXERCISE LEADS TO COMPLEX MULTISYSTEM RESPONSES TO IMPROVE HEALTH OUTCOMES}

Multiples tissues, organs, and systems are influenced by physical activity, or the lack thereof (Table 2).

Table 2. Worsening of maximal functioning in selected major organ/tissue/systems that are caused by the lack of physical activity with growth, maturation, and aging

\begin{tabular}{ll}
\hline Site & \multicolumn{1}{c}{$\begin{array}{c}\text { Organ/tissue/system loses } \\
\text { designated function, most with } \\
\text { aging after maturation }\end{array}$} \\
\hline Brain & $\begin{array}{l}\text { Specific types of cognition } \\
\text { Brain } \\
\text { Heart }\end{array}$ \\
$\begin{array}{ll}\text { Motor coordination and balance } \\
\text { Maximal pumping volume/ } \\
\text { minute }\end{array}$ \\
$\quad$ circulation & $\begin{array}{l}\text { Maximal capacity to supply blood } \\
\text { to working muscles }\end{array}$ \\
Peripheral & Prevention of capillary rarefaction \\
Skeletal muscle & in feet \\
Skeletal muscle & Lower mass and strength \\
Pancreas & Loss of $\beta$ cells \\
Aerobic capacity & Lower \\
Bone & Less mass and strength \\
Liver & Excessive fat storage \\
\hline
\end{tabular}

The higher their maximal function is before the end of each item's maturation, the longer chances are that the quality of life will remain optimal. The breadth of the list implies that a single molecular target will not substitute for appropriate daily physical activity to prevent the loss of all listed items.
To present one extreme, that most will agree, one molecule will not describe the 1000 s of molecules adapting to aerobic, resistance, and coordination exercise training. On the opposite extreme, many could likely agree that usage of the various "omics" underlying all adaptations to physical activity will differ (i.e., not be identical in most aspects) among the next list: various cell types within a tissue/organ, tissues/organs, and various intensities of physical activity (i.e., the thresholds among gene responses for health benefits will differ because of the presence of responders and nonresponders, or protein isoform type); during various types cycling (circadian or menstrual); postprandial versus fasting between meals; male and female; child, adult, and the elderly; trained and untrained; aerobic- and resistance-exercise types; and so forth. Others have repetitively written that only $\sim 59 \%$ of the risk reduction for all forms of CVD have been shown to be caused by effects through traditional factors (Mora et al. 2007; Joyner and Green 2009). Thus, we pose the next question: what is the identity of all molecules in the yet-to-be-discovered gap between our knowledge of single gene functions and the totality of personalized prescription of physical activity to maximize the period of life free of any chronic disease, termed health span?

While approaches using single-gene manipulations are valuable tools, research must also focus on integrating exercise-responsive molecules into networks that maintain or improve health. This process will reveal complex, multisystem, polygenic networking essential for the advancement of many goals pertaining to exercise physiology, such as tailoring exercise prescriptions and implementing personalized medicine. One example is the developing myokine network with auto-, para-, and endocrine molecules. The first myokine interleukin (IL)-6 began to be described as early as 1994 by the Pedersen laboratory (Ullum et al. 1994), with a history of its development as the first exercise myokine recounted in 2007 (Pedersen et al. 2007). Since their discovery, myokine action within and at a distance from their origins in skeletal muscle have been increasingly studied, 
Health Benefits of Exercise

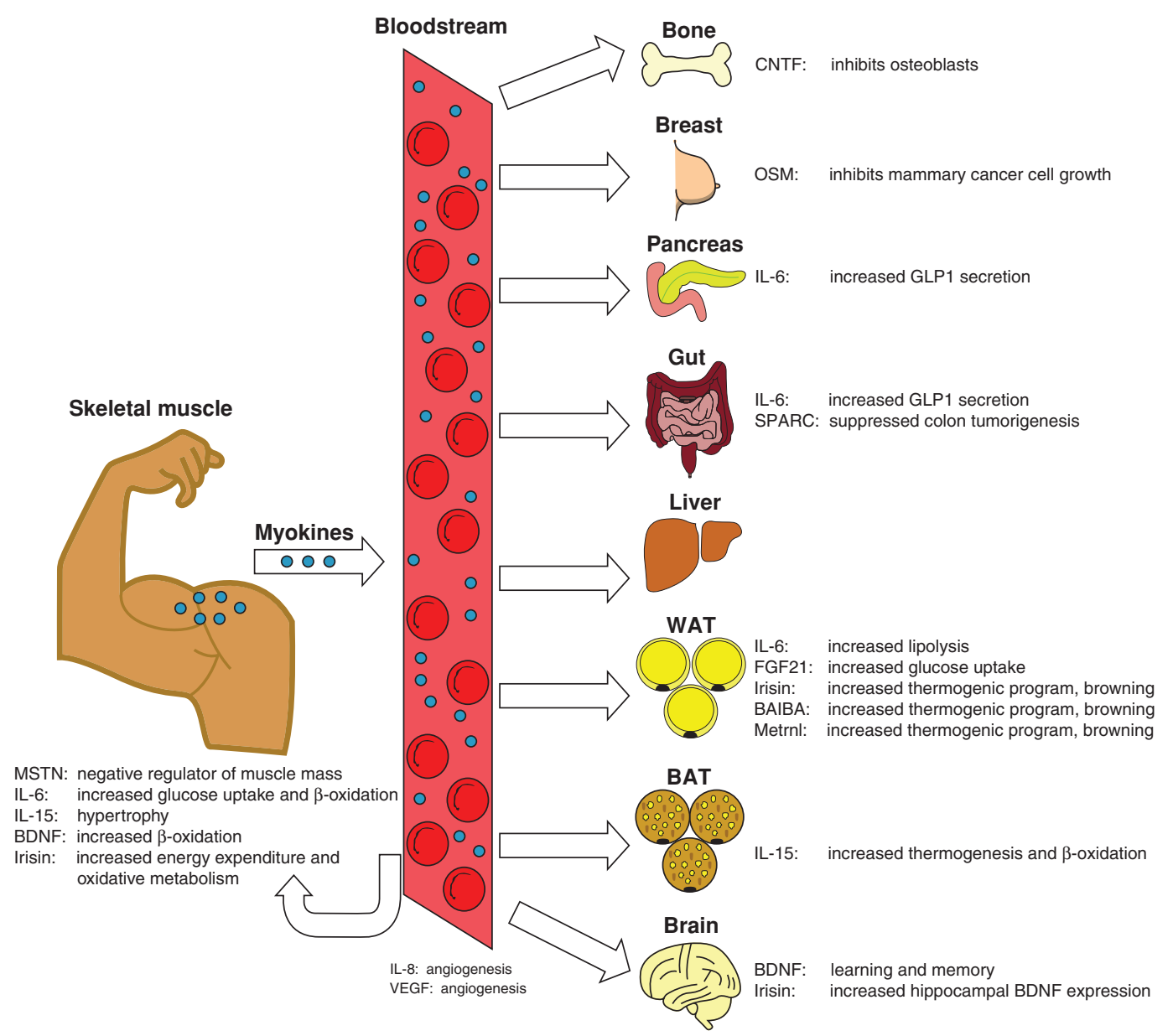

Figure 2. Figure provides an illustration of myokine production by skeletal muscle for actions within or at a distance. Myokine release promotes a high degree of intertissue cross talk. CNTF, Ciliary neurotrophic factor; OSM, oncostatin M; IL, interleukin; BDNF, brain-derived neurotrophic factor; VEGF, vascular endothelial growth factor. (From Schnyder and Handschin 2015; reprinted, with permission, courtesy of PMC Open Access.)

as schematically illustrated by Schnyder and Handschin (2015) (Fig. 2).

Similarly, maximal aerobic exercise is accompanied by tremendous stress on many systems, yet whole-body homeostasis is remarkably maintained. For example, world-class endurance athletes can increase whole-body energy production well over 20-fold (Joyner and Coyle 2008), whereas maintaining blood glucose concentrations at resting levels (Wasserman 2009). Intuitively, such effort would require sophisticated interorgan cross talk and polygenic integration of numerous functions.

\section{Exercise Provides Too Many Benefits to "Fit into a Single Pill"}

Despite the well-known benefits of exercise, most adults and many children lead relatively sedentary lifestyles and are not active enough to achieve the health benefits of exercise (Warburton et al. 2006; Fried 2016). Accelerometry measurements suggest that $>90 \%$ of U.S. individuals $>12 \mathrm{yr}$ of age and $\sim 50 \%$ of children aged 6-11 yr old fail to meet U.S. Federal physical activity guidelines (Troiano et al. 2008). Given this incredibly low compliance, the iden- 
G.N. Ruegsegger and F.W. Booth

tification of genetic and/or orally active agents that mimic the effects of endurance exercise might have high appeal for a majority of sedentary individuals. This high appeal has led to recent identification/development of exercise "mimetics." In 2009, we set criteria for proper usage of the term "exercise mimetic," based upon its common usage (Booth and Laye 2009). We gave the Oxford English Dictionary's definition of mimetic, "A synthetic compound that produces the same (or a very similar) effect as another (especially a naturally occurring) compound." While many exercise "mimetics" activate signaling pathways commonly associated with muscle endurance, these agents have not completely mimicked all effects for all types of exercise. For example, the AMPK activator 5-aminoimidazole-4-carboxamide ribonucleotide (AICAR), when given daily to rats over a 5-wk-period, did not increase maximal oxygen consumption $\left(\mathrm{VO}_{2 \text { peak }}\right)$ in the sedentary group of rats that were forced to run to $\mathrm{VO}_{2 \text { peak }}$ on treadmills, as compared to sedentary rats receiving the vehicle (Toedebusch et al. 2016). Thus, in our opinion, the published claim (Narkar et al. 2008) that AICAR is an exercise mimetic is invalidated because it did not increase $\mathrm{VO}_{2 \text { peak }}$. While these agents may undoubtedly have specific health benefits, it is currently impractical to assume that all of the benefits of exercise can be replaced by "exercise mimetics."

\section{CONCLUDING REMARKS}

Exercise is a powerful tool in the fight to prevent and treat numerous chronic diseases (Table 1). Given its whole-body, health-promoting nature, the integrative responses to exercise should surely attract a great detail of interest as the notion of "exercise is medicine" continues to its integration into clinical settings.

\section{ACKNOWLEDGMENTS}

The authors disclose no conflicts of interest. Partial funding for this project was obtained from grants awarded to G.N.R. (AHA 16PRE2715005).

\section{REFERENCES}

Agudelo LZ, Femenia T, Orhan F, Porsmyr-Palmertz M, Goiny M, Martinez-Redondo V, Correia JC, Izadi M, Bhat M, Schuppe-Koistinen I, et al. 2014. Skeletal muscle PGC- $1 \alpha 1$ modulates kynurenine metabolism and mediates resilience to stress-induced depression. Cell 159: 33-45.

Astrand PO. 1956. Human physical fitness with special reference to sex and age. Physiol Rev 36: 307-335.

Bacon AP, Carter RE, Ogle EA, Joyner MJ. 2013. $\mathrm{VO}_{2 \max }$ trainability and high intensity interval training in humans: A meta-analysis. PLoS ONE 8: e73182.

Beier M, Bombardier CH, Hartoonian N, Motl RW, Kraft GH. 2014. Improved physical fitness correlates with improved cognition in multiple sclerosis. Arch Phys Med Rehabil 95: 1328-1334.

Berchtold NC, Chinn G, Chou M, Kesslak JP, Cotman CW. 2005. Exercise primes a molecular memory for brainderived neurotrophic factor protein induction in the rat hippocampus. Neuroscience 133: 853-861.

Bielak AA, Cherbuin N, Bunce D, Anstey KJ. 2014. Preserved differentiation between physical activity and cognitive performance across young, middle, and older adulthood over 8 years. J Gerontol B Psychol Sci Soc Sci 69: 523532.

Bjerring P, Arendt-Nielsen L. 1990. Inhibition of histamine skin flare reaction following repeated topical applications of capsaicin. Allergy 45: 121-125.

Blair SN, Kohl HWIII, Paffenbarger RSJr, Clark DG, Cooper KH, Gibbons LW. 1989. Physical fitness and all-cause mortality. A prospective study of healthy men and women. JAMA 262: 2395-2401.

Booth FW, Laye MJ. 2009. Lack of adequate appreciation of physical exercise's complexities can preempt appropriate design and interpretation in scientific discovery. J Physiol 587: $5527-5539$.

Booth FW, Chakravarthy MV, Gordon SE, Spangenburg EE. 2002. Waging war on physical inactivity: Using modern molecular ammunition against an ancient enemy. J Appl Physiol (1985) 93: 3-30.

Booth FW, Roberts CK, Laye MJ. 2012. Lack of exercise is a major cause of chronic diseases. Compr Physiol 2: $1143-$ 1211.

Bostrom P, Wu J, Jedrychowski MP, Korde A, Ye L, Lo JC, Rasbach KA, Bostrom EA, Choi JH, Long JZ, et al. 2012. A PGC1- $\alpha$-dependent myokine that drives brown-fatlike development of white fat and thermogenesis. Nature 481: $463-468$.

Boyle JP, Honeycutt AA, Narayan KM, Hoerger TJ, Geiss LS, Chen H, Thompson TJ. 2001. Projection of diabetes burden through 2050: Impact of changing demography and disease prevalence in the U.S. Diabetes Care 24: 19361940.

Boyle JP, Thompson TJ, Gregg EW, Barker LE, Williamson DF. 2010. Projection of the year 2050 burden of diabetes in the US adult population: Dynamic modeling of incidence, mortality, and prediabetes prevalence. Popul Health Metr 8: 29 .

Cappel DA, Lantier L, Palmisano BT, Wasserman DH, Stafford JM. 2015. CETP expression protects female mice 
from obesity-induced decline in exercise capacity. PLoS ONE 10: e0136915.

Carro E, Trejo JL, Busiguina S, Torres-Aleman I. 2001. Circulating insulin-like growth factor I mediates the protective effects of physical exercise against brain insults of different etiology and anatomy. J Neurosci 21: 56785684.

Cotman CW, Berchtold NC. 2002. Exercise: A behavioral intervention to enhance brain health and plasticity. Trends Neurosci 25: 295-301.

Creer DJ, Romberg C, Saksida LM, van Praag H, Bussey TJ. 2010. Running enhances spatial pattern separation in mice. Proc Natl Acad Sci 107: 2367-2372.

Deshmukh A, Coffey VG, Zhong Z, Chibalin AV, Hawley JA, Zierath JR. 2006. Exercise-induced phosphorylation of the novel Akt substrates AS160 and filamin A in human skeletal muscle. Diabetes 55: 1776-1782.

Dwyer-Lindgren L, Mackenbach JP, van Lenthe FJ, Flaxman AD, Mokdad AH. 2016. Diagnosed and undiagnosed diabetes prevalence by county in the U.S., 1999-2012. Diabetes Care 39: 1556-1562.

Fried LP. 2016. Interventions for human frailty: Physical activity as a model. Cold Spring Harb Perspect Med doi: 10.1101/cshperspect.a025916.

Gidlund EK, Ydfors M, Appel S, Rundqvist H, Sundberg CJ, Norrbom J. 2015. Rapidly elevated levels of PGC- $1 \alpha-b$ protein in human skeletal muscle after exercise: Exploring regulatory factors in a randomized controlled trial. $J$ Appl Physiol (1985) 119: 374-384.

Goodyear LJ, Kahn BB. 1998. Exercise, glucose transport, and insulin sensitivity. Annu Rev Med 49: $235-$ 261.

Greenwood BN, Loughridge AB, Sadaoui N, Christianson JP, Fleshner M. 2012. The protective effects of voluntary exercise against the behavioral consequences of uncontrollable stress persist despite an increase in anxiety following forced cessation of exercise. Behav Brain Res 233: 314-321.

Greist JH, Klein MH, Eischens RR, Faris J, Gurman AS, Morgan WP. 1979. Running as treatment for depression. Compr Psychiatry 20: 41-54.

Guerrieri D, van Praag H. 2015. Exercise-mimetic AICAR transiently benefits brain function. Oncotarget 6: $18293-$ 18313.

Gupta S, Rohatgi A, Ayers CR, Willis BL, Haskell WL, Khera A, Drazner MH, de Lemos JA, Berry JD. 2011. Cardiorespiratory fitness and classification of risk of cardiovascular disease mortality. Circulation 123: 1377-1383.

Hattori S, Naoi M, Nishino H. 1994. Striatal dopamine turnover during treadmill running in the rat: Relation to the speed of running. Brain Res Bull 35: 41-49.

Holloszy JO. 2005. Exercise-induced increase in muscle insulin sensitivity. J Appl Physiol (1985) 99: 338-343.

Holloszy JO, Booth FW. 1976. Biochemical adaptations to endurance exercise in muscle. Annu Rev Physiol 38: 273 291.

Holloszy JO, Narahara HT. 1965. Studies of tissue permeability. X: Changes in permeability to 3-methylglucose associated with contraction of isolated frog muscle. $J$ Biol Chem 240: 3493-3500.
Joyner MJ, Coyle EF. 2008. Endurance exercise performance: The physiology of champions. J Physiol 586: 35-44.

Joyner MJ, Green DJ. 2009. Exercise protects the cardiovascular system: Effects beyond traditional risk factors. $J$ Physiol 587: 5551-5558.

Keller P, Vollaard NB, Gustafsson T, Gallagher IJ, Sundberg CJ, Rankinen T, Britton SL, Bouchard C, Koch LG, Timmons JA. 2011. A transcriptional map of the impact of endurance exercise training on skeletal muscle phenotype. J Appl Physiol (1985) 110: 46-59.

Knowler WC, Barrett-Connor E, Fowler SE, Hamman RF, Lachin JM, Walker EA, Nathan DM. 2002. Reduction in the incidence of type 2 diabetes with lifestyle intervention or metformin. N Engl J Med 346: 393-403.

Kobilo T, Yuan C, van Praag H. 2011. Endurance factors improve hippocampal neurogenesis and spatial memory in mice. Learn Mem 18: 103-107.

Kobilo T, Guerrieri D, Zhang Y, Collica SC, Becker KG, van Praag H. 2014. AMPK agonist AICAR improves cognition and motor coordination in young and aged mice. Learn Mem 21: 119-126.

Koch LG, Kemi OJ, Qi N, Leng SX, Bijma P, Gilligan LJ, Wilkinson JE, Wisloff H, Hoydal MA, Rolim N, et al. 2011. Intrinsic aerobic capacity sets a divide for aging and longevity. Circ Res 109: 1162-1172.

Kodama S, Saito K, Tanaka S, Maki M, Yachi Y, Asumi M, Sugawara A, Totsuka K, Shimano H, Ohashi Y, et al. 2009 Cardiorespiratory fitness as a quantitative predictor of all-cause mortality and cardiovascular events in healthy men and women: A meta-analysis. JAMA 301: $2024-$ 2035.

Kokkinos P, Myers J, Faselis C, Panagiotakos DB, Doumas M, Pittaras A, Manolis A, Kokkinos JP, Karasik P, Greenberg M, et al. 2010. Exercise capacity and mortality in older men: A 20-year follow-up study. Circulation 122: 790-797.

Kratz AL, Ehde DM, Bombardier CH. 2014. Affective mediators of a physical activity intervention for depression in multiple sclerosis. Rehabil Psychol 59: 57-67.

Kressler D, Schreiber SN, Knutti D, Kralli A. 2002. The PGC1-related protein PERC is a selective coactivator of estrogen receptor $\alpha$. J Biol Chem 277: 13918-13925.

Kwak SH, Park KS. 2016. Recent progress in genetic and epigenetic research on type 2 diabetes. Exp Mol Med 48: e220.

Larson EB, Carroll ME. 2005. Wheel running as a predictor of cocaine self-administration and reinstatement in female rats. Pharmacol Biochem Behav 82: 590-600.

Leick L, Wojtaszewski JF, Johansen ST, Kiilerich K, Comes G, Hellsten Y, Hidalgo J, Pilegaard H. 2008. PGC- $1 \alpha$ is not mandatory for exercise- and training-induced adaptive gene responses in mouse skeletal muscle. Am J Physiol Endocrinol Metab 294: E463-E474.

Liang X, Liu L, Fu T, Zhou Q, Zhou D, Xiao L, Liu J, Kong Y, Xie H, Yi F, et al. 2016. Exercise inducible lactate dehydrogenase $\mathrm{B}$ regulates mitochondrial function in skeletal muscle. J Biol Chem 291: 25306-25318.

Lin J, Puigserver P, Donovan J, Tarr P, Spiegelman BM. 2002. Peroxisome proliferator-activated receptor $\gamma$ coactivator $1 \beta$ (PGC-1 $\beta$ ), a novel PGC-1-related transcription co- 
G.N. Ruegsegger and F.W. Booth

activator associated with host cell factor. J Biol Chem 277: $1645-1648$.

Lindholm ME, Giacomello S, Werne Solnestam B, Fischer H, Huss M, Kjellqvist S, Sundberg CJ. 2016. The impact of endurance training on human skeletal muscle memory, global isoform expression and novel transcripts. PLoS Genet 12: e1006294.

Lira VA, Benton CR, Yan Z, Bonen A. 2010. PGC-1 $\alpha$ regulation by exercise training and its influences on muscle function and insulin sensitivity. Am J Physiol Endocrinol Metab 299: E145-E161.

Lynch WJ, Peterson AB, Sanchez V, Abel J, Smith MA. 2013. Exercise as a novel treatment for drug addiction: A neurobiological and stage-dependent hypothesis. Neurosci Biobehav Rev 37: 1622-1644.

Maarbjerg SJ, Sylow L, Richter EA. 2011. Current understanding of increased insulin sensitivity after exerciseEmerging candidates. Acta Physiol (Oxf) 202: 323-335.

Mansueto G, Armani A, Viscomi C, D’Orsi L, De Cegli R, Polishchuk EV, Lamperti C, Di Meo I, Romanello V, Marchet S, et al. 2017. Transcription factor EB controls metabolic flexibility during exercise. Cell Metab 25: $182-$ 196.

Mattson MP. 2014. Interventions that improve body and brain bioenergetics for Parkinson's disease risk reduction and therapy. J Parkinsons Dis 4: 1-13.

McKercher C, Sanderson K, Schmidt MD, Otahal P, Patton GC, Dwyer T, Venn AJ. 2014. Physical activity patterns and risk of depression in young adulthood: A 20-year cohort study since childhood. Soc Psychiatry Psychiatr Epidemiol 49: 1823-1834.

Meigs JB, Cupples LA, Wilson PW. 2000. Parental transmission of type 2 diabetes: The Framingham Offspring Study. Diabetes 49: 2201-2207.

Mokdad AH, Marks JS, Stroup DF, Gerberding JL. 2004. Actual causes of death in the United States, 2000. JAMA 291: 1238-1245.

Mora S, Cook N, Buring JE, Ridker PM, Lee IM. 2007. Physical activity and reduced risk of cardiovascular events: Potential mediating mechanisms. Circulation 116: $2110-2118$.

Morris JN, Heady JA, Raffle PA, Roberts CG, Parks JW. 1953. Coronary heart-disease and physical activity of work. Lancet 265: 1053-1057.

Mura G, Moro MF, Patten SB, Carta MG. 2014. Exercise as an add-on strategy for the treatment of major depressive disorder: A systematic review. CNS Spectr 19: 496508.

Myers J, Prakash M, Froelicher V, Do D, Partington S, Atwood JE. 2002. Exercise capacity and mortality among men referred for exercise testing. N Engl J Med 346: 793801.

Narkar VA, Downes M, Yu RT, Embler E, Wang YX, Banayo E, Mihaylova MM, Nelson MC, Zou Y, Juguilon H, et al. 2008. AMPK and PPAR $\delta$ agonists are exercise mimetics. Cell 134: 405-415.

Neeper SA, Gomez-Pinilla F, Choi J, Cotman C. 1995. Exercise and brain neurotrophins. Nature 373: 109.

Nishijima T, Llorens-Martin M, Tejeda GS, Inoue K, Yamamura Y, Soya H, Trejo JL, Torres-Aleman I. 2013. Cessation of voluntary wheel running increases anxiety-like behavior and impairs adult hippocampal neurogenesis in mice. Behav Brain Res 245: 34-41.

Osler ME, Fritz T, Caidahl K, Krook A, Zierath JR, Wallberg-Henriksson H. 2015. Changes in gene expression in responders and nonresponders to a lowintensity walking intervention. Diabetes Care 38: 1154-1160.

Pan XR, Li GW, Hu YH, Wang JX, Yang WY, An ZX, Hu ZX, Lin J, Xiao JZ, Cao HB, et al. 1997. Effects of diet and exercise in preventing NIDDM in people with impaired glucose tolerance. The Da Qing IGT and Diabetes Study. Diabetes Care 20: 537-544.

Park H, Poo MM. 2013. Neurotrophin regulation of neural circuit development and function. Nat Rev Neurosci 14: 7-23.

Pedersen BK, Akerstrom TC, Nielsen AR, Fischer CP. 2007. Role of myokines in exercise and metabolism. J Appl Physiol (1985) 103: 1093-1098.

Pereira AC, Huddleston DE, Brickman AM, Sosunov AA, Hen R, McKhann GM, Sloan R, Gage FH, Brown TR, Small SA. 2007. An in vivo correlate of exercise-induced neurogenesis in the adult dentate gyrus. Proc Natl Acad Sci 104: 5638-5643.

Peterson AB, Hivick DP, Lynch WJ. 2014. Dose-dependent effectiveness of wheel running to attenuate cocaine-seeking: Impact of sex and estrous cycle in rats. Psychopharmacology (Berl) 231: 2661-2670.

Reis FC, Haro AS, Bacurau AV, Hirabara SM, Wasinski F, Ormanji MS, Moreira JB, Kiyomoto $\mathrm{BH}$, Bertoncini CR, Brum PC, et al. 2015. Deletion of kinin B2 receptor alters muscle metabolism and exercise performance. PLoS ONE 10: e0134844.

Rockl KS, Witczak CA, Goodyear LJ. 2008. Signaling mechanisms in skeletal muscle: Acute responses and chronic adaptations to exercise. IUBMB Life 60: 145153.

Ross R, de Lannoy L, Stotz PJ. 2015. Separate effects of intensity and amount of exercise on interindividual cardiorespiratory fitness response. Mayo Clin Proc 90: 15061514.

Rowe GC, El-Khoury R, Patten IS, Rustin P, Arany Z. 2012. PGC- $1 \alpha$ is dispensable for exercise-induced mitochondrial biogenesis in skeletal muscle. PLoS ONE 7: e41817.

Ruas JL, White JP, Rao RR, Kleiner S, Brannan KT, Harrison $\mathrm{BC}$, Greene NP, Wu J, Estall JL, Irving BA, et al. 2012. A PGC- $1 \alpha$ isoform induced by resistance training regulates skeletal muscle hypertrophy. Cell 151: 13191331.

Ruegsegger GN, Toedebusch RG, Braselton JF, Childs TE, Booth FW. 2017. Left ventricle transcriptomic analysis reveals connective tissue accumulation associates with initial age-dependent decline in $\mathrm{VO}_{2 \text { peak }}$ from its lifetime apex. Physiol Genomics 49: 53-66.

Sarzynski MA, Ghosh S, Bouchard C. 2016. Genomic and transcriptomic predictors of response levels to endurance exercise training. J Physiol doi: 10.1113/JP272559.

Schneider J. 2013. Age dependency of oxygen uptake and related parameters in exercise testing: An expert opinion on reference values suitable for adults. Lung 191: 449458. 
Schnyder S, Handschin C. 2015. Skeletal muscle as an endocrine organ: PGC-1 $\alpha$, myokines and exercise. Bone 80: $115-125$.

Schoenfeld TJ, Rada P, Pieruzzini PR, Hsueh B, Gould E. 2013. Physical exercise prevents stress-induced activation of granule neurons and enhances local inhibitory mechanisms in the dentate gyrus. J Neurosci 33: 77707777.

Schuch FB, Vancampfort D, Sui X, Rosenbaum S, Firth J, Richards J, Ward PB, Stubbs B. 2016. Are lower levels of cardiorespiratory fitness associated with incident depression? A systematic review of prospective cohort studies. Prev Med 93: 159-165.

Scott LJ, Erdos MR, Huyghe JR, Welch RP, Beck AT, Wolford BN, Chines PS, Didion JP, Narisu N, Stringham HM, et al. 2016. The genetic regulatory signature of type 2 diabetes in human skeletal muscle. Nat Commun 7: 11764.

Short KR, Vittone JL, Bigelow ML, Proctor DN, Rizza RA, Coenen-Schimke JM, Nair KS. 2003. Impact of aerobic exercise training on age-related changes in insulin sensitivity and muscle oxidative capacity. Diabetes 52: 18881896.

Slentz CA, Aiken LB, Houmard JA, Bales CW, Johnson JL, Tanner CJ, Duscha BD, Kraus WE. 2005. Inactivity, exercise, and visceral fat. STRRIDE: A randomized, controlled study of exercise intensity and amount. J Appl Physiol (1985) 99: 1613-1618.

Slentz CA, Houmard JA, Kraus WE. 2007. Modest exercise prevents the progressive disease associated with physical inactivity. Exerc Sport Sci Rev 35: 18-23.

Stanford KI, Goodyear LJ. 2014. Exercise and type 2 diabetes: Molecular mechanisms regulating glucose uptake in skeletal muscle. Adv Physiol Educ 38: 308-314.

Stephenson EJ, Smiles W, Hawley JA. 2014. The relationship between exercise, nutrition and type 2 diabetes. Med Sport Sci 60: 1-10.

Subbotina E, Sierra A, Zhu Z, Gao Z, Koganti SR, Reyes S, Stepniak E, Walsh SA, Acevedo MR, Perez-Terzic CM, et al. 2015. Musclin is an activity-stimulated myokine that enhances physical endurance. Proc Natl Acad Sci 112: 16042-16047.

Tian Q, Erickson KI, Simonsick EM, Aizenstein HJ, Glynn NW, Boudreau RM, Newman AB, Kritchevsky SB, Yaffe K, Harris TB, et al. 2014. Physical activity predicts microstructural integrity in memory-related networks in very old adults. J Gerontol A Biol Sci Med Sci 69: 12841290.

Timmons JA, Knudsen S, Rankinen T, Koch LG, Sarzynski M, Jensen T, Keller P, Scheele C, Vollaard NB, Nielsen S, et al. 2010. Using molecular classification to predict gains in maximal aerobic capacity following endurance exercise training in humans. J Appl Physiol (1985) 108: 14871496.

Toedebusch RG, Ruegsegger GN, Braselton JF, Heese AJ, Hofheins JC, Childs TE, Thyfault JP, Booth FW. 2016. AMPK agonist AICAR delays the initial decline in life- time-apex $\mathrm{VO}_{2 \text { peak }}$, while voluntary wheel running fails to delay its initial decline in female rats. Physiol Genomics 48: $101-115$.

Trejo JL, Carro E, Torres-Aleman I. 2001. Circulating insulin-like growth factor I mediates exercise-induced increases in the number of new neurons in the adult hippocampus. J Neurosci 21: 1628-1634.

Troiano RP, Berrigan D, Dodd KW, Masse LC, Tilert T, McDowell M. 2008. Physical activity in the United States measured by accelerometer. Med Sci Sports Exerc 40: $181-188$.

Tuomilehto J, Lindstrom J, Eriksson JG, Valle TT, Hamalainen H, Ilanne-Parikka P, Keinanen-Kiukaanniemi S, Laakso M, Louheranta A, Rastas M, et al. 2001. Prevention of type 2 diabetes mellitus by changes in lifestyle among subjects with impaired glucose tolerance. $N$ Engl J Med 344: 1343-1350.

Ullum H, Haahr PM, Diamant M, Palmo J, Halkjaer-Kristensen J, Pedersen BK. 1994. Bicycle exercise enhances plasma IL- 6 but does not change IL-1 $\alpha$, IL-1 $\beta$, IL-6, or TNF- $\alpha$ pre-mRNA in BMNC. J Appl Physiol (1985) 77: 93-97.

van Praag H, Kempermann G, Gage FH. 1999. Running increases cell proliferation and neurogenesis in the adult mouse dentate gyrus. Nat Neurosci 2: 266-270.

Vaughan RA, Gannon NP, Barberena MA, Garcia-Smith R, Bisoffi M, Mermier CM, Conn CA, Trujillo KA. 2014. Characterization of the metabolic effects of irisin on skeletal muscle in vitro. Diabetes Obes Metab 16: $711-718$.

Warburton DE, Nicol CW, Bredin SS. 2006. Health benefits of physical activity: The evidence. CMAJ 174: $801-$ 809.

Wasserman DH. 2009. Four grams of glucose. Am J Physiol Endocrinol Metab 296: E11-E21.

Widenfalk J, Olson L, Thoren P. 1999. Deprived of habitual running, rats downregulate BDNF and TrkB messages in the brain. Neurosci Res 34: 125-132.

Wong KE, Mikus CR, Slentz DH, Seiler SE, DeBalsi KL, Ilkayeva OR, Crain KI, Kinter MT, Kien CL, Stevens RD, et al. 2015. Muscle-specific overexpression of PGC$1 \alpha$ does not augment metabolic improvements in response to exercise and caloric restriction. Diabetes 64: $1532-1543$.

Wrann CD, White JP, Salogiannnis J, Laznik-Bogoslavski D, Wu J, Ma D, Lin JD, Greenberg ME, Spiegelman BM. 2013. Exercise induces hippocampal BDNF through a PGC-1 $\alpha$ /FNDC5 pathway. Cell Metab 18: 649-659.

Zierath JR, Krook A, Wallberg-Henriksson H. 2000. Insulin action and insulin resistance in human skeletal muscle. Diabetologia 43: 821-835.

Zlebnik NE, Anker JJ, Carroll ME. 2012. Exercise to reduce the escalation of cocaine self-administration in adolescent and adult rats. Psychopharmacology 224: 387-400. 


\section{$\&_{\mathrm{CSH}}^{\infty} \&$ Cold Spring Harbor

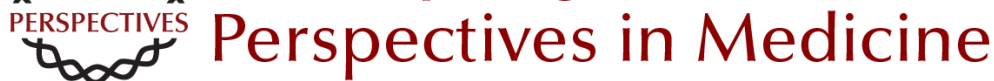

\section{Health Benefits of Exercise}

Gregory N. Ruegsegger and Frank W. Booth

Cold Spring Harb Perspect Med 2018; doi: 10.1101/cshperspect.a029694 originally published online May 15, 2017

\section{Subject Collection The Biology of Exercise}

Exosomes as Mediators of the Systemic

Adaptations to Endurance Exercise Adeel Safdar and Mark A. Tarnopolsky

Molecular Basis of Exercise-Induced Skeletal

Muscle Mitochondrial Biogenesis: Historical

Advances, Current Knowledge, and Future

Challenges

Christopher G.R. Perry and John A. Hawley

Exercise Metabolism: Fuels for the Fire Mark Hargreaves and Lawrence L. Spriet

Health Benefits of Exercise Gregory N. Ruegsegger and Frank W. Booth

Molecular Regulation of Exercise-Induced Muscle

Fiber Hypertrophy

Marcas M. Bamman, Brandon M. Roberts and Gregory R. Adams

Physiological Redundancy and the Integrative

Responses to Exercise Michael J. Joyner and Jerome A. Dempsey

On the Run for Hippocampal Plasticity C'iana Cooper, Hyo Youl Moon and Henriette van Praag

Molecular Basis for Exercise-Induced Fatigue: The Importance of Strictly Controlled Cellular $\mathrm{Ca}$

2+ Handling

Arthur J. Cheng, Nicolas Place and Håkan

Westerblad
Effects of Exercise and Aging on Skeletal Muscle Giovanna Distefano and Bret $H$. Goodpaster

Muscle-Adipose Tissue Cross Talk Kristin I. Stanford and Laurie J. Goodyear

Performance Fatigability: Mechanisms and Task Specificity

Sandra K. Hunter

Adaptations to Endurance and Strength Training David C. Hughes, Stian Ellefsen and Keith Baar

The Bioenergetics of Exercise

$P$. Darrell Neufer

Effects of Exercise on Vascular Function,

Structure, and Health in Humans

Daniel J. Green and Kurt J. Smith

Control of Muscle Metabolism by the Mediator

Complex

Leonela Amoasii, Eric N. Olson and Rhonda

Bassel-Duby

Theoretical and Biological Evaluation of the Link between Low Exercise Capacity and Disease Risk Lauren Gerard Koch and Steven L. Britton

For additional articles in this collection, see http://perspectivesinmedicine.cshlp.org/cgi/collection/ 